\title{
Measurements of Standby Power Consumption of Domestic Appliances in Albania
}

\author{
Marijon Pano
}

Department of Mathematics, Informatics and Physics, Fan S. Noli University

\begin{abstract}
Nearly all modern domestic appliances used in typical homes consume some energy when they are left on standby mode or even switched off. I investigated the variation in standby power consumption in five homes in Korça city. The typical standby energy loss for studied homes ranged from 8-115 W, with an average of $37 \mathrm{~W}$. This corresponded to $3 \%-20 \%$ of the homes annual electricity use. This loss and the associated cost are not high enough to get noticed by the consumer. However, when such power losses of all domestic appliances are aggregated at the level of a country, the amount becomes significant and cannot be ignored. The appliances with the largest standby losses were coffee machines, televisions, set-top boxes and printers. They account for a significant proportion of the electricity consumption in more and more Albanian households. The wide variation in the standby power of appliances providing the same benefits indicates that producers are able to reduce standby losses without degrading performance. The standby power consumption of various domestic appliances was determined using an energy smart meter and data-logger connected with a computer. The purpose of this paper is to estimate how much power is wasted in a typical Albanian home due to household appliances being in the standby mode.
\end{abstract}

Keywords: Standby power consumption, energy loss, vampire power, leaking electricity, domestic appliances, appliance efficiency.

\section{Introduction}

Standby power, vampire power, phantom load, or leaking electricity are general terms commonly used to describe the energy consumed by the electric appliances when they are not performing their principal function. In the beginning of 1990, standby power loss was a phenomenon for electronic devices rather than for electric appliances. Whereas now, almost every household appliance like air-conditioners, freezers, refrigerators, microwave ovens and washing machines, need a small amount of electricity to maintain signal reception capability i. e. remote control, monitoring temperature, powering internal clock and continuous display. A significant number of studies have been conducted in developed countries, such as in Germany (Rath et al. 1997), Netherlands (H. Siderius 1998), and the United States (A. Meier, K. Rosen, 1999). Those studies have found that standby power accounts for as much as $10 \%$ of national residential electricity use. The typical electricity loss for an appliance can range from as little as $1 \mathrm{~W}$ to as high as $30 \mathrm{~W}$ (B. Mohanty 2001). At first glance, the loss of such kind seems to be low, but the combined effect of all appliances, the power consumption of which varies from less than 1 Watt to 30 Watts, is having significant impact on total household electricity consumption. For instance, in the United States, standby losses account for about $5 \%$ of total residential electricity while $15 \%$ in Italy (Camilleri et al. 2002). The standby energy for all households in the EU-27 countries amounts to about $43 \mathrm{TWh}$ in total, and it is responsible for about 19 million tons of $\mathrm{C} 02$ per year. The standby power consumption of all the office equipment used in EU-27 countries is estimated to be about 9TWh (Bertoldi et al., 2009). Altogether, standby power use is roughly responsible for $1 \%$ of global $\mathrm{CO} 2$ emissions. According to the International Energy Agency, by 2030, $15 \%$ of the total appliance electricity consumption in Europe could be due to standby functions. Figure 1 shows that the standby power loss of developed and developing countries varies up to $10 \%$ due to various social and technological factors. 


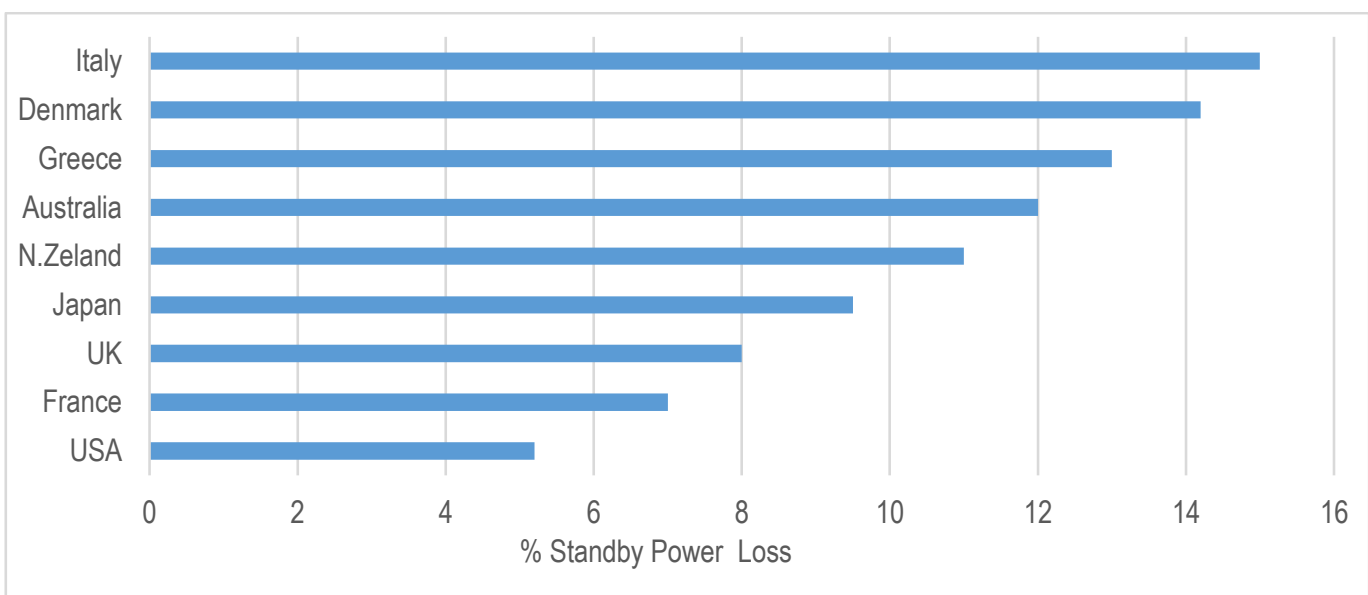

Figure 1. Share of standby power losses in total electricity used in the residential sector. (M. Violet, S. Iwisi, 2009)

The objectives of the study were to measure the standby power losses of household appliances and estimate potential savings from reductions in standby power use. I have examined the energy use by domestic appliances in five typical homes in Korça city, Albania. The standby power consumption of various domestic appliances was determined using an energy smart meter. The experimental results show that the standby power for various office appliances is a real concern. The results from this study can also help to formulate policies and programs to reduce standby power in Albanian homes.

\section{Methodology}

A sample of five homes was recruited from a range of different income levels. This group of five homes is too small to accurately represent the standby losses for every home, but it involves a great diversity of appliances and situations. In each home, I measured each appliance's power consumption, while the appliance was in use, in standby (passive and/or active) where applicable, and briefly measured the house's total electricity consumption, with all appliances switched off. I tried to perform as many measurement modes as possible in order to achieve the maximum information about products power consumption. I used a common measurement methodology and the same equipment in all measurements. Appliance standby power was measured at the lowest level with a watt meter equipment model EKM-OmniMeter I v. 3. The meter was connected to the mains and to the computer (it can export data to computer in excel format through EKM Dash software). Then the product was plugged into the power cable connected to EKM meter through current transformer (CT) and the measurement could be started. The total standby power for each home was calculated by summing the individual appliance measurements.

\section{Results}

About 75 domestic appliances were investigated from five houses studied. Table 1 summarizes those measurements.

The majority of these appliances are classified in 3 main levels: entertainment, ICT, and miscellaneous.

Table 1. Measurements of standby power consumption by type of appliance

\begin{tabular}{|l|l|l|l|}
\hline Domestic Appliance & Minimum (Watt) & Maximum (Watt) & Average Load (Watt) \\
\hline Entertainment & 2 & 6 & 4.3 \\
\hline TV & 3 & 7 & 4.7 \\
\hline CD player & 4 & 30 & 10.3 \\
\hline VCR & 4 & & \\
\hline
\end{tabular}




\begin{tabular}{|l|l|l|l|l|}
\hline Digital receiver & \multicolumn{2}{|l|}{2.8} & 10 & 7.2 \\
\hline ICT & 1.5 & 8 & 4.2 \\
\hline Desktop tower & 2 & 10 & 3.2 \\
\hline Monitor & 2.3 & 16 & 4.3 \\
\hline Laptop & 2.1 & 13.5 & 5.1 \\
\hline Printer all in one & 1.2 & 2.3 & 1.3 \\
\hline Cordless phone & 3 & 7 & 4 \\
\hline Modem & \multicolumn{3}{|l|}{} \\
\hline Miscellaneous & 2 & 6 & 4.2 \\
\hline Oven + cooktop & 1 & 7 & 3.2 \\
\hline Microwave & 4 & 60 & 25 \\
\hline Coffee-espresso & 1 & 4 & 3 \\
\hline Dishwasher & 2 & 6 & 4 \\
\hline Air conditioner & & \multicolumn{3}{|l|}{} \\
\hline
\end{tabular}

The ranges of standby in this study are also similar if compared to other compilations of measurements such as Meier et al. 1999 and Huber 1997. The households had an average of 19 appliances with standby power, ranging from 1 to $60 \mathrm{~W}$. Standby accounted for $3 \%$ to $20 \%$ of total annual electricity consumption. The appliances with the largest standby losses were coffee-espressos, televisions, and printers. Each home's annual electricity consumption was also displayed (based on utility monthly bills). Average annual electricity use was $4110 \mathrm{kWh} / \mathrm{yr}$. All five homes used wood stoves and natural gas for space heating.

Table 2. Measurements of annual standby power consumption in the surveyed houses

\begin{tabular}{|l|l|l|l|l|}
\hline Home & $\begin{array}{l}\text { Annual } \\
\text { Electricity Use } \\
\text { (KWh/yr) }\end{array}$ & Standby Power (W) & $\begin{array}{l}\text { Relative Standby Power } \\
\text { (KWh/yr) }\end{array}$ & $\begin{array}{l}\text { Standby Power as \% of } \\
\text { Annual Electricity Use }\end{array}$ \\
\hline 1 & 2591 & 15 & 132 & $5 \%$ \\
\hline 2 & 4945 & 115 & 1009 & $20 \%$ \\
\hline 3 & 1212 & 8 & 70 & $6 \%$ \\
\hline 4 & 7852 & 25 & 219 & $3 \%$ \\
\hline 5 & 3950 & 22 & 193 & $5 \%$ \\
\hline Average & 4110 & 37 & 325 & $8 \%$ \\
\hline
\end{tabular}

\section{Conclusions}

The survey conducted in five houses is too small to accurately represent the standby losses for every house, but it involves a great diversity of appliances and situations, and can provide new insights to the scope of the problem and the opportunities for reducing it. According to the resulting measurements, the biggest attention regarding standby losses must be paid to the following appliances: coffee-espresso, TV, VCR, printers, computer monitors, and even laptop chargers. The device should be switched off when it is not in use, especially at night or at weekends, when possible, and looking to the future we should consider choosing equipment with class A++ (low standby) energy efficiency, in order to reduce standby energy 
consumption for the benefit of individuals and of the whole nation. Consumer awareness about standby power consumption should be increased by launching publicity campaigns and with energy efficiency labeling schemes to be initiated by the Ministry of Energy and Industry.

\section{References}

[1] Meier, K. Rosen, 1999. Leaking Electricity in Domestic Appliances. Proceedings of 50 International Appliance Technical Conference, West Lafayette, Indiana, Steering Committee of the IATC.

[2] Mohanty, 2001. Standby Power Losses in Household Electrical Aplliances and office Equipment. The French Agency for the Environment and Energy Management.

[3] H. Siderius, 1998. Standby Consumption in Households. Van Holsteijn en Kemma, Delft, The Netherlands.

[4] International Energy Agency, 1999. Workshop on international action to reduce standby power waste of electrical equipment. IEA, webpage www. iea. org/standby/outcomes. htm.

[5] M. Camilleri, A. Pollard, A. Stoecklein, L. Amitrano and N. Issacs, 2002. The Baseload and Standby Power Consumption of New Zealand Houses. Paper No. 100, IRHACE Technical Conference, Palmerston North.

[6] M. Violet, S. Iwisi, 2009. Estimation of Standby Power and Energy Losses in South African Homes. Doctoral Thesis, University of the Witwatersrand, Johannesburg.

[7] P. Bertoldi, 1999, Electricity Consumption and Efficiency Trends in European Union. Status Report.

[8] U. Rath, M. Hartmann, A. Praeffke \& C. Mordziol, 1997. Klimaschutz durch Minderung von Leerlaufverlusten bei Elektrogeräten. Forschungsbericht 20408541 UBA-FB 97-071. Berlin: Umweltbundesamt.

[9] W. Huber, 1997. Standby Power Consumption in U. S. Residences. LBNL-41107. Lawrence Berkeley National Laboratories, Berkeley, Ca. USA. 